điểm 5 năm sau ghép. Các chỉ số Ure máu, protein niệu, hồng câuu niệu giữa 2 nhóm này không khác nhau.

\section{TÀI LIẸU THAM KHẢO}

1. Kotton C.N. và Fishman J.A. (2005). Viral Infection in the Renal Transplant Recipient. JASN, 16(6), 1758-1774.

2. Giáo trình bệnh truyên nhiễm Y5 Y HN.2009.

3. Trân Xuân Trường T.N.S. Kết quả theo dõi và điều trị sau ghép thận có nhiếm vi rút viêm gan $C$ tại bệnh viện Chợ Rẫy ( Kỷ yếu công trình ghép thận bệnh viện Chợ Rẫy 2011-2016).

4. Hồ Mạnh Lính. (2016). Nghiên cứu tình trạng nhiếm virus viêm gan $B$ ở bệnh nhân sau ghép

thận, 5-7, 11-13, 19-28.
5.Trân Xuân Trường T.N.S. Tình hình theo dõi và điêuu trị HBV sau ghép thận tại bệnh viện Chợ Rẫy (Kỷ yếu công trình ghép thẩn BV Chở Rẫy 2011-2016).

6. Emori C.T., Perez R.M., Matos C.A.L. de và cộng sự. (2014). Acute exacerbation of chronic hepatitis $B$ virus infection in renal transplant patients. Brazilian Journal of Infectious Diseases, 18(6), 625-630.

7. Cập nhật đîêu trị viêm gan C mạn-2019, <http:// vasld.com.vn/cap nhat-dieu-tri-viem-gan-c-man-2019>.

8. Sund S., Reisæter A.V., Fauchald P. và cộng sự. (1999). Living donor kidney transplants: a biopsy study 1 year after transplantation, compared with baseline changes and correlation to kidney function at 1 and 3 years. Nephrology Dialysis Transplantation, 14(10), 2445-2454.

\title{
ĐẶC ĐIỂM GIẢI PHẪU LÂM SÀNG VẠT D.I.E.P TRONG TẠO HÌNH VÚ SAU CẮT BỎ TUYẾN VÚ DO UNG THƯ
}

\section{TÓM TẮT}

Mục tiêu: Mô tả các đặc điểm giải phẫu lâm sàng vạt mạch xuyên động mạch thượng vị sâu dưới (D.I.E.P: Deep Inferior Epigastric Perforator Flap) trong tạo hình vú sau cắt bỏ toàn bộ tuyến vú do ung thư. Phương pháp nghiên cứu: Nighiên cứu mô tả trên 29 bệnh nhân được phẫu thuật tạo hình vú sử dụng vat D.I.E.P tại Bệnh viện Đại học Y Hà Nội từ 08/2019 tới 05/2021. Kết quả: Kích thước vạt phẫu tích trung bình dài $35,0 \pm 4,33 \mathrm{~cm}$, rộng $12,41 \pm 1,9$ $\mathrm{cm}$. Thể tích vạt phẩu tích trung bình 573,62 $\pm 130,39$ $\mathrm{ml}$, thể tích vạt sử dụng trung bình 408,97 $\pm 111,27$ ml (thấp nhất là $240 \mathrm{ml}$, lớn nhất là $750 \mathrm{ml}$ ). Thể tích vat sử dụng tạo hình lớn hơn thể tích vú cắt bỏ trung bình 10,02 $\pm 7,4 \%$. Số lượng mạch xuyên sử dung trung bình 1,97 $\pm 0,5$ mạch xuyên/ vạt. 100\% trường hợp vat có ít nhất 1 mạch xuyên lớn ở trong đường tròn bán kính $5 \mathrm{~cm}$ với tâm là rốn. Chiều dài cuống mạch trung bình là $8,95 \pm 1,69 \mathrm{~cm}$. Kết luân: Vạt D.I.E.P là chất liệu phù hợp và đáng tin cậy với những ưu điểm về giải phẩu hằng đinh, cuống mach dài và cấp máu an toàn, kích thước và thể tích vạt phù hợp với tao hình vú.

Từ khóa: Vạt mạch xuyên động mạch thượng vị sâu dưới, vạt D.I.E.P, tạo hình vú, giải phẩu lâm sàng.

\section{SUMMARY \\ CLINICAL ANATOMY OF D.I.E.P FLAP IN BREAST RECONSTRUCTION \AFTER TOTAL MASTECTOMY BY CÁCER}

*Trường Đại học Y Hà Nọi.

Chịu trách nhiệm chính: Phan Tuấn Nghĩa

Email: nghiapt@live.com

Ngày nhận bài: $11 / 7 / 2021$

Ngày phản biên khoa hoc: 14/8/2021

Ngày duyệt bài: 30/8/021
Objective: This paper aims to describe the clinical anatomical characteristics of the Deep Inferior Epigastric Perforator flap (D.I.E.P) in breast reconstruction after total mastectomy. Methods: The study was carried out on 29 patients at Hanoi Medical University hospital from August 2019 to May 2021. Results: the average flap size was $35,0 \pm 4,33 \mathrm{~cm}$ long and $12,41 \pm 1,9 \mathrm{~cm}$ wide. The average volume of dissected flap was $573,62 \pm 130,39 \mathrm{ml}$, the average volume of reconstruction flap was $408,97 \pm 111,27 \mathrm{ml}$ (the lowest was $240 \mathrm{ml}$, the highest was $750 \mathrm{ml}$ ). The flap used for reconstruction was 10,02 $\pm 7,4 \%$ larger than the removed breast volume. The average number of perforator used was $1,97 \pm 0,5$ perforator per flap, and the distance from the position of the perforator penetrating the superficial fascia of the abdomen to the umbilicus was $3,85 \pm 1,58 \mathrm{~cm}$. All cases have at least one large perforating vessel within a circle of radius $5 \mathrm{~cm}$ with center at the umbilicus. The average pedicle length was $8,95 \pm 1,69 \mathrm{~cm}$. Our conclusion once again emphasizes that the DIEP flap is a suitable and reliable material for the breast reconstruction.

Keywords. Deep inferior epigastric perforator flap, D.I.E.P flap, clinical anatomical characteristics.

\section{I. ĐĂTT VẤN ĐỀ}

Sử dụng chất liệu tự thân trong tạo hình vú là một trong những phương pháp được nhiều tác giả lựa chọn. Trong đó vạt D.I.E.P được các tác giả đồng thuận là lựa chọn hàng đầu để tạo hình vú sau cắt bỏ tuyến vú do ung thư với các ưu điểm là chất liệu tự thân, có khả năng chịu được quá trình hóa xa trị, tương đồng màu sắc, tính chất mềm mại đờng thời ít ảnh hưởng tới chức năng và cải thiện hình thể nơi cho vạt. Vạt D.I.E.P là vạt da cân mõ vùng thành bụng dưới, được cấp máu bởi các mạch xuyên da từ động 
mach thương vị dưới sâu, tách ra từ đônng mach chậu ngoài. Các mạch xuyên có xu hướng tập trung quanh rốn và gần đường giữa hơn, đặc biệt là các mạch xuyên lớn (đường kính $\geq$ $0.5 \mathrm{~mm}$ ). Kích thước vạt lấy theo $\mathrm{y}$ văn có thể trung bình $30-45 \mathrm{~cm}$ chiều dài và $12-15 \mathrm{~cm}$ chiêu rộng ${ }^{1}$. Vạt có thể được sử dụng dưới dạng vạt da cân mõ hoăc vat da cân cớ. Có sự khác biệt về vùng cấp máu vạt, theo Hartramf chia thành 4 vùng, trong đó vùng $\mathrm{I}$, II, III là các vùng được đảm bảo cấp máu an toàn, vùng IV được coi là vi trí cấp máu kém nhất ${ }^{2}$. Vat được sử dựng dưới dang tự do có sử dụng kỹ thuât vi phẫu, đòi hỏi phẫu thuật viên cần có nhiều kinh nghiệm trong quá trình bóc tách cũng như nối mạch, do đó nắm bắt được đặc điểm, giải phẫu vạt, đặc biệt trên lâm sàng là rất quan trong. Nhiều nghiên cứu của các tác giả nước ngoài về đặc điểm giải phẫu vạt D.I.E.P đã được công bố, tuy nhiên ở Việt Nam, do nhiều yếu tố khác nhau, chưa có nhiều nghiên cứu về giải phẫu vạt D.I.E.P trong thực hành lâm sàng. Do đó chúng tôi thực hiện nghiên cứu này nhằm mục đích mô tả đặc điểm giải phẫu lâm sàng vạt D.I.E.P trong tạo hình vú sau cắt bỏ tuyến vú do ung thư.

\section{II. ĐỐI TƯỢNG VÀ PHƯƠNG PHÁP NGHIÊN CỨU}

2.1. Đối tượng nghiên cứu. Thực hiện nghiên cứu trên 29 bệnh nhân được chẩn đoán ung thư giai đoạn 1-2, có chỉ định phẫu thuật cắt tuyến vú toàn bộ. Bệnh nhân có tình trạng thừa da mõ thành bụng được chỉ định tạo hình vú tức thì bằng vat D.I.E.P, không có các chống chỉ định với phẩu thuật kéo dài và vi phẫu thuật.

Thời gian nghiền cứu từ 09/2019 tới 05/202, thực hiện tại đơn vị phẫu thuật tạo hình thẩm mỹ công nghê cao - Bệnh viên Đại học Y Hà Nội.

\subsection{Phương pháp nghiên cứu}

2.2.1. Thiết kế nghiên cứu. Nghiên cứu tiến hành theo phương pháp mô tả cắt ngang không đối chứng.

\subsubsection{Qui trình phẫu thuật}

Chuẩn bị mổ: Bệnh nhân được vẽ thiết kế vạt, siêu âm Doppler cầm tay xác định sơ bộ vị trí mạch xuyên. Vạt hình elip với bờ trên của vạt đi qua điểm ngay trên rốn, bờ dưới vạt trùng với nếp lằn bụng, 2 điểm phía bên hình elip được xác định là 2 gai chậu trước trên 2 bên (Hình $1 \mathrm{~A}$ ).

Thực hiện phẫu thuật: Bệnh nhân được mê nội khí quản, tư thế nằm ngửa 2 gối gấp $90^{\circ}$. Phẫu thuật thực hiên gồm 2 ekip phẩu thuật tiến hành cùng nhau. Ế kíp 1 (bác sĩ ung bướu) cắt bỏ tuyên vú toàn bộ và nạo vét hạch. Toàn bộ tuyến vú cắt bỏ được đo thể tích bằng phương pháp chiếm thể tích nước trong bình (sử dụng bình thủy tinh có phân độ dung tích 2 lít, đổ ngập 1 lít $\mathrm{NaCl} 0,9 \%$. Sau đó đặt tổ chức vú ngập hoàn toàn trong bình và xác định thể tích nước tăng thêm) và gửi làm giải phẫu bệnh. Ê kíp 2 (bác sĩ phẫu thuật tạo hình) bóc vạt da mõ thành bụng dưới. Rạch da từ bờ dưới, bóc tách vạt từ dưới lên trên, xác định mạch xuyên chính, ưu tiên các mạch lớn, đập rõ. Kẹp thắt các mạch xuyên còn lại. Bóc tách theo đường đi mạch xuyên đã chọn tới cuống mạch D.I.E.P qua cơ thẳng bung. Để lại một đảo cân quanh vị trí mạch xuyên đi qua lớp mạc nông. Kẹp cắt cuống mạch tại nếp lằn bẹn, nẩng vạt rời hoàn toàn. Đo kích thước chiều dài và rộng vạt phẫu tích được, đo khoảng cách từ vị trí mạch xuyên xuyên qua cân nông tới rốn, chiều dài các nhánh mạch xuyên từ vị trí tách từ cuống mạch chính tới vị trí xuyên qua cân nông, chiêu dài cuống mach chính. Đo thể tích vạt theo phương pháp chiếm thể tích nước trong bình (tương tư như đo thể tích vú cắt bỏ) (Hình 1B).
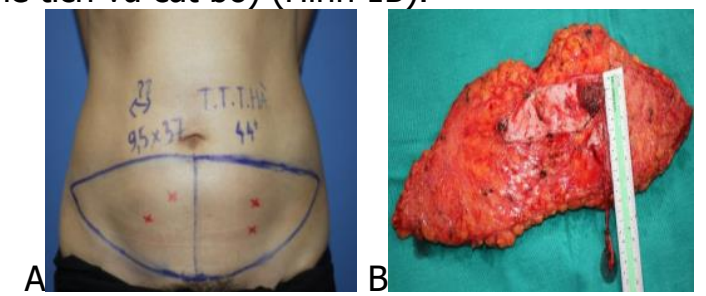

\section{Hình 1. A. Thiêt kế vạt D.I.E.P trước phẫu \\ thuât. B. Vat được cắt rời cuống mach}

Tùy theo vị trí, chiều dài cuống mach, hình thể vú bên đối diện để lựa chọn cuống mạch nhân. Vạt được đặt theo hướng chéo vát từ trên xuống dưới, từ trong ra ngoài sao cho bờ trên của vạt (phía gần rốn) quay xuống dưới.

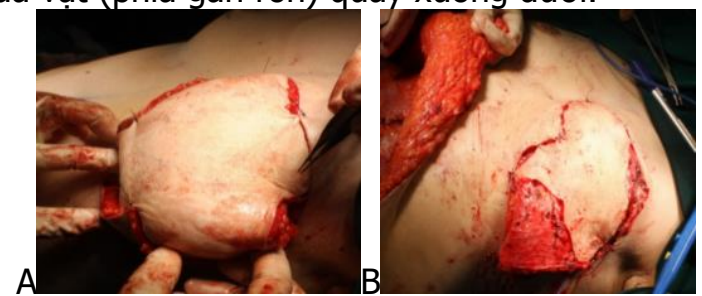

Hình 2. A: Vạt được khâu định hình xác định hinh thể vú tao hinh. B: Xác đinh phần da vú thiếu, lạng bỏ thượng bi phần da vạt còn lại

Tiến hành cố định tạm thời vạt, nối động mạch và tĩnh mạch vạt với cuống mạch nhận dưới kính hiển vi phẫu thuật. Cố định đầu trền vào vào KLS II canh ức, bờ dưới vạt khâu cuôn tạo hình thể vú, cắt bỏ phần thừa, ưu tiên cắt vùng IV theo phân loại cấp máu của Hartrampf. Khâu thử định hình vạt, sau đó xác định phần da 
vú thiếu, tiến hành lạng bỏ phần thượng bì để lại đảo da tương ứng với khuyết da vú, phần vạt còn lại được sử dụng để độn tạo thể tích. Đặt dẫn lưu hố nách và dẫn lưu dưới vat. Khâu cố định vat, đóng vết mổ. Nơi cho vạt đóng như đối với phẫu thuật tạo hình thành bụng toàn thể có chuyển rốn.

Trong suốt quá trình phẫu thuật, các đặc điểm về giải phẫu lâm sàng vạt D.I.E.P (số lượng, vị trí mạch xuyên sử dụng, chiều dài cuống mạch) được ghi nhận và lưu trữ.

\section{KẾT QUẢ NGHIÊN CỨU}

Số lượng mạch xuyên sử dụng trung bình là $1,97 \pm 0,5$ mạch xuyên/vạt. Với tổng cộng 57 mạch xuyên được sử dụng trong tất cả các trường hợp. Trong đó có 4 trường hợp (chiếm $13,8 \%$ ) chúng tôi sử dụng cuống mạch với 1 mạch xuyên duy nhất, 22 trường hợp $(75,9 \%)$ chúng tối dụng cuống mạch với 2 mạch xuyên và có 3 trường hợp $(10,3 \%)$ sử dụng cuống mạch 3 mạch xuyên. Vị trí mạch xuyển cách rốn trung bình là $3,85 \pm 1,58 \mathrm{~cm}(1,0-9,0 \mathrm{~cm})$.

Chiều dài cuống mạch vạt trung bình là 8,95 $\pm 1,69 \mathrm{~cm}(4-12 \mathrm{~cm})$. Với 12/29 (41,4\%) trường hợp cuống vạt cùng bên với vú cắt bỏ và 17/29 (58.6\%) trường hợp cuống mạch đối bên. Không có sự khác biệt về chiều dài cuống mạch giữa 2 nhóm vạt với cuống mạch cùng bên và đối bên $(\mathrm{p}=0,569>0,05, \mathrm{CI}=95 \%)$. Cũng không có sự khác biệt về chiều dài cuống mạch giữa nhóm vạt sử dụng cuống mạch vú trong với nhóm vạt sư dụng cuống mạch ngực lưng $(p=0,064>$ $0,05, \mathrm{CI}=95 \%)$.

Kích thước vạt phẫu tích trung bình dài 35,0 $\pm 4,33 \mathrm{~cm}(27-45 \mathrm{~cm})$, rộng $12,41 \pm 1,9 \mathrm{~cm}$ (9 $-16 \mathrm{~cm}$ ). Kích thước vạt sử dụng trung bình dài $28,32 \pm 3,88(20-38 \mathrm{~cm})$, chiều rộng bằng với vat được phẫu tích (Bảng 1 ). Thể tích tuyến vú cắt bỏ trung bình $378,79 \pm 113,84 \mathrm{ml}$ (200 $700 \mathrm{ml})$. Thể tích vạt phẫu tích trung bình 573,62 $\pm 130,34 \mathrm{ml}(340-900 \mathrm{ml})$, thể tích vạt sử dụng trung bình 408,97 $\pm 111,27 \mathrm{ml}$ (thấp nhất là 240 $\mathrm{ml}$, lớn nhất là $750 \mathrm{ml}$ ) (Bảng 2). Thể tích vú cắt bỏ có mối liên hệ tương quan đồng biến với thể tích vạt phẫu tích, với hệ số tương quan $r=$ 0,774 , giá trị $p=0,00<0,01$. Thể tích vạt sử dụng lớn hơn thể tích vú cắt bỏ trung bình 10,02 $\pm 7,4 \%(0-23 \%)$.

\begin{tabular}{|c|c|c|}
\hline & Dài (cm) & Rộng (cr \\
\hline ích thước vạt phấu tích & $35,0 \pm 4,33$ & \\
\hline $\begin{array}{c}\text { Kích thước vạt sử } \\
\text { dụng }\end{array}$ & $\begin{array}{c}28,32 \pm \\
3,88\end{array}$ & 12, \\
\hline
\end{tabular}

Bảng 2. Thể tích vú cắt bỏ và thể tích vạt

\begin{tabular}{|c|c|c|c|}
\hline & $\begin{array}{c}\text { Thế tích } \\
(\mathbf{m l})\end{array}$ & $\begin{array}{c}\text { Min } \\
(\mathbf{m l})\end{array}$ & $\begin{array}{c}\text { Max } \\
(\mathbf{m l})\end{array}$ \\
\hline Thế tích vú & $378,79 \pm$ & 200 & 700 \\
cắt bỏ & $113,84 \mathrm{ml}$ & $\mathrm{ml}$ & $\mathrm{ml}$ \\
\hline Thế tích vạt & $573,62 \pm$ & 340 & 900 \\
phẫu tích & $130,34 \mathrm{ml}$ & $\mathrm{ml}$ & $\mathrm{ml}$ \\
\hline $\begin{array}{c}\text { Thế tích vạt } \\
\text { sứ dụng }\end{array}$ & $408,97 \pm$ & 240 & 750 \\
\hline
\end{tabular}

Kết quả gần sau mố, tỷ lệ vạt sống hoàn toàn là $27 / 29(93,1 \%)$, có 2 trường hợp phải tháo bỏ vạt (chiếm 6,9\%), nguyên nhân của cả 2 trường hợp tháo bỏ vạt hoàn toàn được xác định do tắc tĩnh mạch. Khổng có mối liên hệ vê tỷ iệ thất bại vạt giữa nhóm vạt sử dụng 1 mạch xuyên và nhóm với nhóm sử dụng $\geq 2$ mạch xuyên ( $p=$ $1,000, C I=99 \%)$. Có $1 / 29$ trường hợp tắc tînh mạch sau mổ được can thiệp giải quyết lấy bỏ huyết khối, tái thông mạch (chiếm 3,44\%), 1 trường hợp ứ máu tĩnh mạch sau mổ được can thiệp nối bổ sung thêm 1 tĩnh mạch (chiếm 3,44\%).

\section{BÀN LUẬN}

Tạo hình vạt DIEP đã trở thành lựa chọn hàng đầu cho các phẫu thuật tạo hình vú sử dụng chất liệu tự thân với những ưu điểm về tính chất tương đồng, độ mềm mại cũng như ít ảnh hưởng tới chức năng nơi cho vạt. Chỉ định tạo hình vú tức thì sử dụng vạt DIEP rất rộng rãi và với các nhu cầu khác nhau của bệnh nhân, phương pháp cũng như cách sử dụng thiết kế vạt cũng thay đổi tùy theo cơ sở vật chất và thói quen của phẩu thuật viên.

Trên 29 trường hợp, chúng tôi sử dụng trung bình $1,97 \pm 0,49$ mạch xuyên/vạt, kết quả này không khác biệt với nghiên cứu của Ireton ${ }^{3}$ là 1,57 mạch xuyền được sử dụng trên mỗi vạt $(p$ $<0,001, \mathrm{CI} 99 \%)$. Trong đó chúng tôi chủ yếu sử dụng cuống mạch với 2 mạch xuyên để đảm bảo cấp máu vạt được đầy đủ. Những trường hợp chúng tôi sử dụng cuống mạch 1 mạch xuyên là những trường hợp trên lâm sàng chúng tôi đánh giá rất kỹ mạch xuyên đường kính lớn và đập tốt. Và cả 4 trường hợp sử dụng cuống vạt 1 mạch xuyên vạt đều sống tốt. vị trí mạch xuyên chúng tôi xác định trong phẫu thuật cách rốn trung bình $3,92 \mathrm{~cm}$, nhỏ hơn so với nghiên cứu của Ireton ${ }^{3}$ là $4,51 \mathrm{~cm}$. Lý giải điều này có thể là do chúng tôi sử dụng 2 mạch xuyên ở những vị trí tương đối gần nhau và gần rốn hơn để tăng sự di động của cuống mạch, giúp quá trình nối mạch thuận tiện hơn. Và cũng tương tự với nhận định của các tác giả nước ngoài, $100 \%$ các trường hợp vạt chúng tôi đều phát hiện có ít nhất 1 mạch xuyền lớn (đường kính $\geq 0,5 \mathrm{~mm}$ ) 
trong vòng tròn bán kính $5 \mathrm{~cm}$ tính từ rốn. Điều này rất có ý nghĩa trong việc bóc tách vạt nhanh chóng và giúp tối đa hóa chiều dài của cuống mạch vạt. Chúng tôi cũng cải tiến kỹ thuật, để lại đảo cân quanh vị trí mạch xuyên xuyên qua cân cơ thẳng bụng qua đường giữa sang bên đối diện, vì theo giải phẫu, khi mạch xuyên qua cân cơ sẽ đi tới tham gia vào mạng mạch dưới trung bì ${ }^{3}$, do đó theo kinh nghiệm của chúng tôi để lại một phân cân quanh mạch bắc qua đường giữa giúp bảo tồn tối đa sự cấp máu từ mạch xuyên sang nửa bên vạt đối diện. Nghiên cứu chúng tôi cũng nhận thấy không có mối liên hệ giữa số lượng mạch xuyên vạt được sử dụng với tỷ lệ thất bại của phương pháp. Kết quả này cũng tương tự với kết quả của Grover ${ }^{4}$ trên 395 vat D.I.E.P. Tuy nhiên do cõ̃ mẫu còn nhỏ do đó kết quả của chúng tôi còn nhiều hạn chế về thống kê.

Chiều dài cuống mạch phấu tích trung bình là $8,95 \pm 1,69 \mathrm{~cm}$ tương tự với nghiên cứu của Ulusal $^{5}$ hay của Ireton ${ }^{3}$ là $9,05 \mathrm{~cm}$ trên lâm sàng. Tất cả các trường hợp chúng tôi đều phẫu tích cuống mạch vạt dài nhất có thể để thuận lợi khi xoay chuyển vạt trong quá trình tái tạo hình thể vú. Với chiều dài này chúng tôi nhận thấy là hoàn toàn đủ để có thể đặt vạt tạo hình ngay cả sử dụng cuống mạch ngực lưng là mạch nhận. Vì theo các tác giả sử dụng cuống mạch ngực lưng làm cuống mạch nhận sẽ yêu cẩu cần cuống mạch vạt dài để có thể đặt vạt ở vị trí phù hợp. Nghiên cứu cho thây không có mối liên hê giữa việc sử dụng cuống mạch cùng bên hay đối bên tới tỷ lệ thành công vạt. Theo kinh nghiệm chúng tôi nhận thấy sử dụng cuống mach cùng bên và đối bên cũng không có sự khác biệt quá lớn, tuy nhiên chúng tôi vân ưu thích sử dụng cuống mạch đối bên hơn do vị trí phù hợp với phương pháp đặt vạt chéo vát, phần gần rốn của vạt hướng xuống dưới và vào trong.

Kích thước vạt phẫu tích trung bình 35,0 \pm $4,33 \mathrm{~cm}$ dài và $12,41 \pm 1,9 \mathrm{~cm}$ chiều rộng, kết quả này tương tự với kích thước vạt được mô tả kinh điển trong y văn là từ $30-45 \mathrm{~cm}$ chiều dài và $12-15 \mathrm{~cm}$ chiều rộng ${ }^{1}$. Điều này cho thấy mặc dù người châu Á nói chung có khung người và thể tích người nhỏ hơn so với người Âu Mỹ, tổ chức dưới da cũng mỏng hơn ${ }^{6}$, tuy nhiên kích thước vạt cũng tương tự như người Âu Mỹ. Lý giải điều này có thể do người Việt Nam nói riêng có tỷ lê sinh con thứ 2, thứ 3 lớn, tình trang sa trễ, thừa da mõ thành bung nhiếu do đó kích thước vạt thành bụng tạo hình cũng tương tự với các tác giả khác trên thế giới. Tuy nhiên số lượng bệnh nhân của chúng tôi cũng chưa đủ lớn và đối tượng là trên những bệnh nhân sau sinh, có tình trạng thừa da mõ thành bụng, do đó kết quả phân tích còn hạn chế.

Thể tích vạt phấu tích với thể tích vú cắt bỏ có mối liên hệ tương quan đồng biến nhau, trong đó thể tích vạt phẫu tích luôn lơn hơn thể tích vú cắt bỏ. Ngay cả khi cắt bỏ vùng IV của vạt (theo cấp máu của Hartrampf) thể tích vạt sử dụng cũng lớn hơn thể tích vú cắt bỏ. Điều đó lần nữa nhấn mạnh sự phù hợp của vạt D.I.E.P để độn thể tích sau cắt bỏ toàn bộ tuyến vú. Thể tích vat sử dung chúng tôi cũng lớn hơn so với thể tích vú cắt bỏ trung bình là $10,02 \pm 7,4 \%$. Tại sao có sự chênh lệch này?. Theo nghiên cứu của Myung ${ }^{7}$ trên vạt tự thân tạo hình vú có sự giảm thể tích vạt theo thời gian, đặc biệt trong 3-6 tháng đầu. Sau thời gian này, sư thay đổi thể tích vú vẫn tiếp tục xảy ra, tuy nhiên sự thay đổi là không đáng kể. Trên y văn cũng chưa có nghiên cứu cơ chế cụ thể cự sự thay đổi thể tích vat theo thời gian. Theo nghiên cứu gần đây của Wilting ${ }^{8}$, tỷ lệ thể tích vạt đo trên phim cắt lớp vi tính giảm trung bình là $11,1 \%$ sau 3 và 6 tháng tao hình vú so với ngay sau mổ. Do đó, viêc chúng tôi để thể tích vat lớn hơn trong phẫu thuật chính nhằm mục đích đạt được hình thể thẩm mỹ phù hợp, tương xứng theo thời gian khi quá trình thay đối thể tích vạt diễn ra. Không những vây, có $6 / 29(29,7 \%)$ trường hợp thể tích vạt tạo hình chúng tôi lấy lớn hơn thể tích vú cắt bỏ $\geq 20 \%$. Lý giải điêu này, do đặc điểm của người Việt Nam chúng tôi nhận thấy thường có tình trang vú teo lép, do đó chúng tôi định lượng thể tích vú bên tạo hình to hơn để có kế hoạch tạo hình bên vú lành sau này theo nhu cầu của bệnh nhân.

\section{KẾT LUẬN}

Trong nghiên cứu của chúng tôi, kích thước của vạt D.I.E.P lớn, trung bình $35,0 \pm 4,33 \mathrm{~cm}$ dài và $12,41 \pm 1,9 \mathrm{~cm}$ chiều rộng, với thể tích vạt trung bình phẫu tích được từ $340-900 \mathrm{ml}$. Giải phẫu lâm sàng của vạt DIEP hằng định với $100 \%$ trường hợp chúng tôi thấy ít nhất 1 mạch xuyên ở vị trí cách rốn $5 \mathrm{~cm}$. Cuống mạch vat phẫu tích dài $8,95 \pm 1,69 \mathrm{~cm}$. Chính nhờ các đắc điểm này mà vạt D.I.E.P được xem là chất liệu rất phù hợp và mang lại kết quả rất tốt trong phẫu thuật tạo hình vú sau cắt bỏ ung thư.

\section{TÀI LIÊU THAM KHẢO}

1. Hamdi M, Rebecca A. The Deep Inferior Epigastric Artery Perforator Flap (DIEAP) in Breast Reconstruction. Semin Plast Surg. 2006;20(2):95102. doi:10.1055/s-2006-941716 
2. Holm C, Mayr M, Höfter E, Ninkovic $M$. Perfusion zones of the DIEP flap revisited: a clinical study. Plast Reconstr Surg. 2006;117(1):37-43. doi:10.1097/01.prs.0000185867.84172.c0

3. Ireton JE, Lakhiani C, Saint-Cyr M. Vascular anatomy of the deep inferior epigastric artery perforator flap: a systematic review. Plast Reconstr Surg. 2014;134(5): 810e-821e. doi:10.1097/ PRS.0000000000000625

4. Grover R, Nelson JA, Fischer JP, Kovach SJ, Serletti JM, Wu LC. The impact of perforator number on deep inferior epigastric perforator flap breast reconstruction. Arch Plast Surg. 2014;41(1):63-70. doi:10.5999/aps.2014.41.1.63

5. Ulusal BG, Cheng M-H, Wei F-C, Ho-Asjoe M, Song $\mathbf{D}$. Breast reconstruction using the entire transverse abdominal adipocutaneous flap based on unilateral superficial or deep inferior epigastric vessels. Plast Reconstr Surg. 2006;117(5):13951403; discussion 1404-1406. doi:10.1097/ 01.prs.0000207401.78491.43

6. Deurenberg $P$, Deurenberg-Yap M, Guricci S. Asians are different from Caucasians and from each other in their body mass index/body fat per cent relationship. Obes Rev Off J Int Assoc Study Obes. 2002;3(3):141-146. doi:10.1046/j.1467789x.2002.00065.X

7. Myung $\mathbf{Y}$, Son $\mathbf{Y}, \operatorname{Nam} \mathbf{T}$, et al. Objective assessment of flap volume changes and aesthetic results after adjuvant radiation therapy in patients undergoing immediate autologous breast reconstruction. PLOS ONE. 2018;13(5):e0197615. doi:10.1371/journal.pone.0197615

8. Wilting $\mathbf{F N H}$, Hameeteman $\mathbf{M}$, Tielemans HJP, Ulrich DJO, Hummelink S. "Threedimensional evaluation of breast volume changes following autologous free flap breast reconstruction over six months." Breast Off ] Eur Soc Mastology. 2020;50:85-94. doi:10.1016/ j.breast.2020.02.005

\title{
KẾT QUẢ PHẪU THUÂTT NộI SOI SAU PHÚC MẠC CẮT NANG THẬN TẠI BỆNH VIỆN BẠCH MAI
}

\author{
Lorn Sopheak $^{1}$, Nguyễn Minh Tuấn ${ }^{2}$, Trần Hiếu Học ${ }^{1,2}$ \\ Trần Mạnh Hùng ${ }^{2}$, Nguyễn Trường Giang ${ }^{2}$

\section{RESULTS OF RETROPERITONEOSCOPIC SURGERY OF SIMPLE RENAL CYST AT BACH MAI HOSPITAL}

\section{TÓM TẮT}

Mục tiêu: Mô tả một số đặc điểm lâm sàng, cận lâm săng và đánh giá kết quả phẫu thuật nội soi sau phúc mạc cắt nang thận. Đối tượng và phương pháp: mô tả hồi cứu các bệnh nhân được chẩn đoán xác định và mổ nội soi sau phúc mạc cắt nang thận tại Bênh viên Bach Mai từ 01/2020 đến 06/ 2021. Kểt quả: 46 bệnh nhân với tuổi trung bình là $57,72 \pm$ $14,84(19-83)$, tỉ lệ nữ/nam là $1 / 1$. Đau thắt lưng là triệu chứng chính gặp ở $87 \%$. Thăm dò hình ảnh thấy đường kính nang, tỷ lê nhóm nang có kích thước 50$100 \mathrm{~mm}$ và thành mỏng trên chụp lớp ví tính và siêu âm lần lượt là $77,48 \pm 26,53 \mathrm{~mm}(45-183 \mathrm{~mm})$ và $79,17 \pm 26,05 \mathrm{~mm} \quad(45-183 \mathrm{~mm}), 76,1 \%$ và $78,3 \%$, $91,3 \%$ và $93,5 \%$. Thời phẫu thuâtt trung bình là $54,74 \pm 16,6$ phút. Tai biến: 1 trường hợp chảy máu $2,2 \%$. Biến chứng sau mổ: 2 bệnh nhân chảy máu qua dấn lưu 4,3\%. Thời gian nằm viện là $3,22 \pm 1,01$ ngày (2-6). Kết luân: Nôi soi sau phúc mạc cắt nang thận là phương pháp phẫu thuật an toàn và hiệu quả trong điều tri nang thân.

Tư khoá: Nang thận, cắt nang thận, phẫu thuật nội soi sau phúc mạc.

\section{SUMMARY}

${ }^{1}$ Trường Đại học Y Hà Nội

${ }^{2}$ Bênhh viện Bạch Mai

Chịu trách nhiệm chính: Lorn Sopheak.

Email: Iorn.sopheak@gmail.com

Ngày nhận bài: 13/7/2021

Ngày phản biên khoa hoc: 15/8/2021

Ngày duyệt bài: 30/8/2021
Objective: Description of some clinical, paraclinical characteristics and evaluation of the results of retroperitoneoscopic renal cystectomy. Subjects and methods: Retrospective description of the cases diagnosed simple renal cyst and underwent retroperitoneoscopic simple renal cystectomy at Bach Mai Hospital from January/2020 to June/2021. Results: There were 46 patients who underwent retroperitoneoscopic simple renal cystectomy with an average age of $57.72 \pm 14.84$ years old (range from 19 to 83 years). Ratio of male/female were $1 / 1$. The flank or back pain were the most common sign which happened in $87 \%$ patients. The average diameter in CT scaner of cyst was $77.48 \pm 26.53 \mathrm{~mm}(45-183 \mathrm{~mm})$, the size of $50-100 \mathrm{~mm}$ and thin cyst wall were $76.1 \%$ and $91.3 \%$, respectively. The average diameter in Echography of cyst was $79.17 \pm 26.05 \mathrm{~mm}$ (45-183mm), the size of $50-100 \mathrm{~mm}$ and thin cyst wall were $76.1 \%$ and $91.3 \%$, respectively. The operative time was $54.74 \pm 16.6$ minutes. The perioperative accident of bleeding was $2.2 \%$. The complications were postoperative bleeding $4.3 \%$. Median length of hospital stay was $3.22 \pm 1.01$ days (2-6). Conclusion: The retroperitoneoscopic cystectomy is a safe and effective procedure in the treatment of renal cysts with the low morbidity and excellent result.

Keyword: Kidney cysts, renal cystectomy, Retroperitoneoscopic surgery.

\section{I. ĐĂT VẤN ĐỀ}

Nang thận là tổn thương dạng nang lành tính 